\title{
ANÁLISE SILVICULTURAL DO ANGICO E DA AROEIRA NA ARBORIZAÇÃO DA CIDADE DE BRASÍLIA/DF
}

\author{
José Maximiano de Mello Jacinto ${ }^{1}$, José Imaña-Encinas ${ }^{2}$, Gustavo Silva Ribeiro ${ }^{3}$, Caio César \\ Teobaldo $^{4}$, Christian Rainier Imaña ${ }^{5}$
}

(recebido em 01.04.2008 e aceito para publicação em 22.01.2009)

\begin{abstract}
RESUMO
O presente estudo analisou o comportamento dendrométrico silvicultural das espécies angico Anadenanthera macrocarpa (Benth.) Brenan, e aroeira Myracrodruon urundeuva Fr. All. na arborização urbana da cidade de Brasília, Distrito Federal. Foram realizadas medições de diâmetro, altura do fuste e altura total de 21 árvores de angico na idade de 18 anos, e em 12 árvores de aroeira na idade de 14 anos. As mesmas árvores foram medidas novamente 7 anos após. Além das medições dendrométricas também foram consideradas as características silviculturais da espécie. Ambas as espécies apresentaram bom desenvolvimento podendo ser indicadas para programas de arborização em áreas urbanas de Brasília e seu entorno.
\end{abstract}

Palavras-chave: silvicultura urbana, florestas urbanas, arborização urbana.

\footnotetext{
1 Engenheiro Florestal, Mestre em Ciências Florestais, Brasília, DF, josemaximiano.jacinto@caixa.gov.br

${ }^{2}$ Engenheiro Florestal, PhD em Ciências Florestais, UnB, Departamento de Engenharia Florestal, Brasília, DF, imana@unb.br

${ }^{3}$ Engenheiro Florestal, SQS 204 - Bloco C, Apto 105, Bairro Asa Sul, Brasília - DF. CEP: 70.234030. E-mail: gustavo.s.ribeiro@hotmail.com.

${ }^{4}$ Acadêmico do Curso de Engenharia Florestal, UnB, Departamento de Engenharia Florestal, caioflorestal@hotmail.com

${ }^{5}$ Estatístico, Secretaria da Fazenda de Minas Gerais, christian_bsb@hotmail.com
} 


\title{
SILVICULTURAL SURVEY OF ANGICO AND AROEIRA IN THE ARBORICULTURE OF BRASILIA
}

\begin{abstract}
The present study was undertaken to analyse the behavior of two species used in the arborization of Brasília and the viability to use them in urban forests. Those species were "angico" Anadenanthera macrocarpa (Benth.) Brenan and "aroeira" Myracrodruon urundeuva Fr. All. In year 2000 we measured the diameter, height of the trunk and total height of 21 trees of "angico" on the age of 18, and 12 trees of "aroeira" on the age of 14 years old. At the year 2007 the same trees were measured. Besides dendrometrics measurements were also surveyed the silvicultural characteristics of these species. Both species showed good development and can be displayed for programmes of reforestation in urban areas around the Federal District.
\end{abstract}

Key words: urban silviculture, urban forest, urban trees.

\section{INTRODUÇÃO}

Denomina-se área verde urbana todo o revestimento vegetal natural preservado nas cidades ou aquele artificial implantado pelo homem e que tem, entre outras funções, a de atuar como elemento de bem-estar ou lazer. Logradouros públicos e jardins particulares ou comunitários constituem-se áreas verdes da "urbe", sendo a árvore o elemento primordial, em todas as circunstâncias (BRANDÃO \& BRANDÃO, 1992).

Lombardo (1990) destaca o papel das áreas verdes como mitigadoras dos efeitos antrópicos adversos no clima urbano. Segundo a autora, as árvores e outros vegetais, interceptando, absorvendo, refletindo e transmitindo radiação solar, captando e transpirando água e interferindo com a direção e velocidade dos ventos, podem ser extremamente eficientes na melhoria do clima urbano. Cabe destacar, também, a ação purificadora das árvores na atmosfera urbana através da fixação de poeiras e gases tóxicos, principalmente, pela captura de $\mathrm{CO}_{2}$ e liberação de oxigênio através dos mecanismos fotossintéticos. $\mathrm{O}$ plantio de árvores proporciona benefícios ecológicos, sociais e econômicos (LEAL et al., 2008) além de espirituais e históricos (SETH, 2004).

Para Lewis (1997) as árvores no ambiente urbano carregam, além dos benefícios anteriormente citados, a ornamentação da paisagem com suas formas fazendo contraponto 
Análise silvicultural do angico e da aroeira...

à estrutura plana dos edifícios. O autor destaca que, com freqüência, as árvores servem como elementos valorizadores de estruturas arquitetônicas e de méritos estéticos. Agem, também, como guarda-sóis naturais, provendo conforto fisiológico através de suas copas que sombreiam ruas, passeios, praças, gramados e jardins. Os benefícios ecológicos referem-se à melhoria microclimática e amenização da poluição atmosférica e acústica (BIONDI e ALTHAUS, 2005). Milano (1987) cita também que a arborização urbana reduz os efeitos da instabilidade microclimática e das poluições atmosférica, hídrica, sonora e visual que afetam a qualidade de vida urbana, resultando na necessidade de melhor planejar e manter as árvores em áreas urbanas. Para Detzel (1992), a arborização de cidades, realizada de forma planejada, apresenta-se como uma opção para a melhoria da qualidade ambiental urbana tendo em vista os benefícios diretos e indiretos proporcionados pelas áreas verdes e árvores ao longo das ruas.

O plantio e manutenção de árvores em assentamentos urbanos eram, até há pouco tempo, assunto exclusivo de urbanistas e arquitetos paisagistas. A arborização urbana é um quesito importante para proporcionar um ambiente físico saudável (ROSSATTO et al., 2008). Os engenheiros florestais começaram a participar do processo de arborização nas cidades e zonas do entorno somente nestas últimas duas décadas. No Brasil, provavelmente a partir da década de 80 , houve uma tendência de se dar um enfoque mais amplo e de cunho técnico-científico a esse processo, contemplando não apenas o aspecto paisagístico, mas, também, os efeitos benéficos dessa prática à sociedade. A essa abordagem denomina-se silvicultura urbana.

A silvicultura urbana é um ramo especializado da silvicultura, tendo por finalidade o cultivo e a ordenação de árvores com objetivo de aproveitar a contribuição atual e potencial que estas podem dar ao bem-estar da população urbana, tanto do ponto de vista fisiológico como sociológico e econômico (KUCHELMEISTER \& BRAATZ 1993). Para Carter (1996), a silvicultura urbana inclui atividades de manejo florestal que se realizam nas cidades, nas zonas suburbanas e nas zonas marginais, do entorno ou de contato com os terrenos agrícolas.

A vegetação urbana, como em qualquer sistema ecológico, desempenha um papel relevante, sobretudo por ser a base em que se apóiam os ecossistemas e da qual depende alguns ciclos de vida da forma ornitológica. Ao observar-se a cidade como ecossistema é necessário ressaltar a importância da diversidade de espécies como um aspecto benéfico no ambiente urbano. Cestaro (1985) destaca a importância da existência da vegetação na área urbana, através de seus tipos e efeitos benéficos, bem como as condições urbanas prejudiciais às espécies vegetais, afirmando que quanto maior a diversidade de espécies vegetais, maior será a possibilidade de instalação definitiva de uma fauna mais diversificada, 
e quanto maior o número de espécies presentes no ecossistema, maior será a sua capacidade de resistir a variações e de absorver impactos negativos do meio em que está.

Hoje, o plantio de árvores no espaço urbano já não pode ser realizado de forma amadorística, e as necessidades urbanas a serem mitigadas passam, além do estético, pelos fatores, psicológico, econômico, social, político e da própria sustentabilidade florestal. Essa visão mais globalizante e essa necessidade técnica de amenizar problemas tão variados fazem com que seja procurado um termo mais abrangente: floresta urbana (GONÇALVES, 1999; GONÇALVES \& PAIVA, 2006).

Pereira (1998) enfatiza que, quando se discute a questão dos índices de metros quadrados de áreas verdes por habitante, deve-se considerar, também, o tipo e densidade de massa arbórea e sua distribuição balanceada na malha urbana. Esses fatores conjugados, associados a inúmeros outros agentes sócio-econômico-culturais podem contribuir para a melhoria da qualidade de vida nas cidades.

Anadenanthera macrocarpa (Benth.), conhecida como angico ou angico-vermelho, pertence à família Fabaceae (TROPICOS, 2008). Segundo Lorenzi (2002) é uma planta que floresce exuberantemente todos os anos, tornando-a excelente para a ornamentação e arborização de parques e jardins. Esta espécie, naturalmente, é muito freqüente em áreas de cerradões e matas de galerias do Brasil Central e produz anualmente uma grande quantidade de sementes. (LORENZI, 2002).

Myracrodruon urundeuva Allemao, conhecida como aroeira, pertence á família Anacardiaceae (TROPICOS, 2008). As árvores desta espécie possuem uma copa piramidal muito vistosa, sendo indicada para a arborização e ornamentação em geral (LORENZI, 2002).

As duas espécies fazem parte das 249 espécies levantadas por Silva Júnior et al. (2001) na arborização da cidade de Brasília.

O objetivo deste estudo foi identificar o desenvolvimento das espécies de Anadenanthera macrocarpa (Benth.) e Myracrodruon urundeuva Allemao visando a sua utilização na silvicultura urbana da cidade de Brasília, DF.

\section{MATERIAL E MÉTODOS}

O presente trabalho foi realizado na área urbana do Plano Piloto da cidade de Brasília, Distrito Federal. A cidade localiza-se no Planalto Central do Brasil, área inserida no bioma Cerrado. Os locais de crescimento dos angicos e aroeiras estão caracterizados pela presença de um relevo plano, com altitude de pouco mais de $1.050 \mathrm{~m}$, em solos do tipo latossolo, pobres em nutrientes e bastantes profundos. Segundo a classificação de Köppen 


\section{Análise silvicultural do angico e da aroeira...}

o clima na região consiste em tropical de altitude, tipo Cwa (PINTO, 1993). A temperatura média anual está em torno de $20,4^{\circ} \mathrm{C}$ e a oscilação mensal está na média de $3,3^{\circ} \mathrm{C}$. A média máxima é de $28,5^{\circ} \mathrm{C}$ e a média mínima de $12,0^{\circ} \mathrm{C}$ (NIMER, 1989). Temperaturas abaixo de $10^{\circ} \mathrm{C}$ ocorrem em poucos dias no período de inverno. Em setembro constatam-se as mais baixas médias de umidade (EMBRAPA, 1978).

Os dados acerca da época de plantio e características dos respectivos sítios de plantio foram obtidos junto ao Departamento de Parques e Jardins (DPJ) do Governo do Distrito Federal.

As primeiras medições de 21 angicos e 12 aroeiras foram realizadas nos meses de maio e junho do ano de 2000, e a segunda medição ocorreu em dezembro de 2007. A população amostral ficou restrita aos locais indicados na Tabela 1.

Tabela 1 - Locais em Brasília (DF) e anos de plantio dos angicos e aroeiras

\begin{tabular}{lccc}
\hline \multicolumn{1}{c}{ Espécie } & $\begin{array}{c}\text { Ano de } \\
\text { plantio }\end{array}$ & Local & Indivíduos \\
\hline Anadenanthera macrocarpa & 1981 & SQS 407 & 21 \\
Myracrodruon urundeuva & 1985 & SQN 406 & 06 \\
Myracrodruon urundeuva & 1985 & SQN 410 & 06 \\
\hline SQS = Super Quadra Sul; SQN = Super Quadra Norte.
\end{tabular}

De cada indivíduo arbóreo foram efetuadas as seguintes medições: diâmetro do fuste à altura do peito (DAP) utilizando uma suta de $80 \mathrm{~cm}$; diâmetro da copa ( $\left.D_{\text {copa }}\right)$ identificada pela sua projeção no solo efetuando-se duas medidas transversais com uma trena de $25 \mathrm{~m}$; altura da primeira bifurcação $\left(\mathrm{H}_{\text {bif }}\right)$, altura do início da copa $\left(\mathrm{H}_{\text {copa }}\right)$ e altura total $\left(\mathrm{H}_{\text {total }}\right)$ do indivíduo. As alturas foram determinadas com o Hipsômetro Haga.

\section{RESULTADOS E DISCUSSÃO}

Angico - Anadenanthera macrocarpa (Benth.) Brenan, família: Fabeceae (TROPICOS, 2008)

A Anadenanthera macrocarpa é uma espécie heliófita com potencial para reflorestamento ambiental e recuperação de áreas degradadas (LORENZI, 2002). O mesmo autor indica que seu crescimento é relativamente rápido, e possui grande expansão de copa e considerável poder de regeneração, além de ser indicada na formação de florestas urbanas, em parques, jardins e áreas verdes mais amplas, às margens de estradas e vias de tráfego. Sua madeira pode ser empregada na construção rural, para produção de caibros, esquadrias, batentes, 
vigas, postes, mourões, tacos, dormentes, além de fornecer lenha e carvão de boa qualidade (RIZZINI, 1987).

A Tabela 2 mostra os resultados obtidos na avaliação dos indivíduos arbóreos (Figura 1) mensurados da espécie A. macrocarpa, nas idades de 18 e 25 anos, obtidos respectivamente nos anos de 2000 e 2007. Para cada idade correspondente, são apresentados os valores paramétricos encontrados, que traduz a fonte de dados a serem analisados.

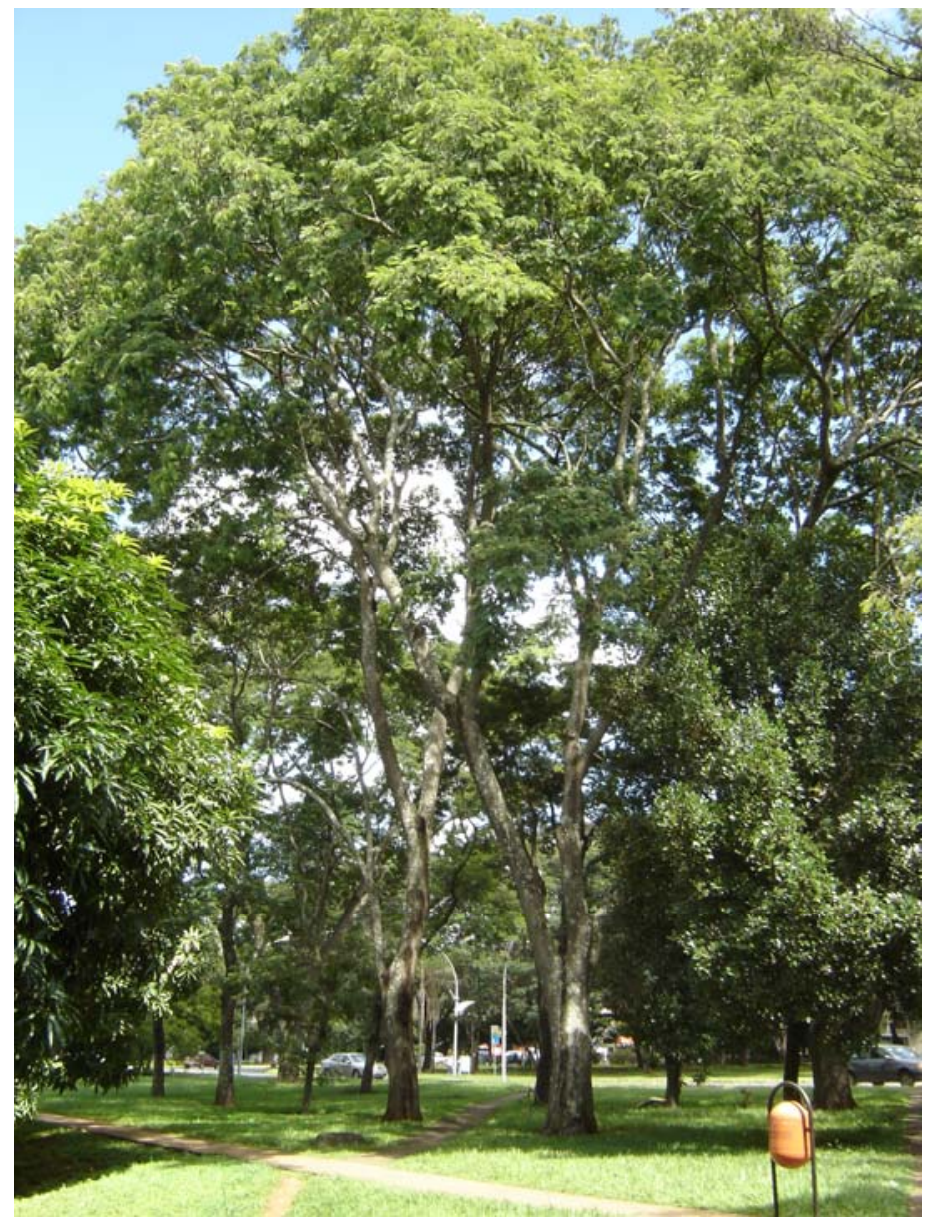

Figura 1 - Indivíduos de A. macrocarpa mensurados na SQS 407, Brasília, DF. 
Análise silvicultural do angico e da aroeira...

Tabela 2 - Resultados das variáveis dendrométricas consideradas

\begin{tabular}{lc}
\hline Dados da Espécie & Anadenanthera macrocarpa \\
\hline Idade & $\mathbf{1 8}$ anos \\
DAP médio & $59,1 \mathrm{~cm}$ \\
CV \% & 29,6 \\
H média 1 ${ }^{\text {a }}$ bifurcação & $3,1 \mathrm{~m}$ \\
H média início da copa & $7,2 \mathrm{~m}$ \\
H média total & $18,5 \mathrm{~m}$ \\
H média copa & $11,3 \mathrm{~m}$ \\
Diâmetro da Copa ( $\left.\mathrm{D}_{\text {copa }}\right)$ & $11,3 \mathrm{~m}$ \\
Idade & $\mathbf{2 5} \mathbf{a n o s}$ \\
DAP médio & $64,4 \mathrm{~cm}$ \\
CV \% & 30,3 \\
H média 1 ${ }^{\mathrm{a}}$ bifurcação & $3,4 \mathrm{~m}$ \\
H média início da copa & $9,2 \mathrm{~m}$ \\
H média total & $23,5 \mathrm{~m}$ \\
H média copa & $14,3 \mathrm{~m}$ \\
Diâmetro da Copa ( $\left.\mathrm{D}_{\text {copa }}\right)$ & $16,1 \mathrm{~m}$ \\
\hline
\end{tabular}

Os resultados obtidos para as 21 árvores de angico mensuradas na idade de 18 anos foram: altura média total de 18,5 m, altura do fuste até o início da copa igual a 7,2 m e DAP de 59,1 cm. Já para idade de 25 anos a espécie obteve um ganho percentual de 27,03\% em relação à altura média total, 27,78\% em relação à altura do fuste até o início da copa, $42,48 \%$ em relação ao diâmetro da copa projetado no solo e um ganho de $8,97 \%$ em relação ao DAP médio. Além das relações acima, a altura média da copa obteve um acréscimo de $26,55 \%$. Com isso verifica-se que os indivíduos estão investindo seu potencial de crescimento em altura e diâmetro. Nas regiões de Cerrado e Caatinga, o angico apresenta porte menor, com altura variando de $3 \mathrm{~m}$ a $15 \mathrm{~m}$ (CARVALHO, 1994). Outro estudo realizado no Parque da Cidade, em Brasília, essa mesma espécie atingiu 7,7 m de altura e 21,07 cm de DAP aos 12 anos (MACHADO et al., 1990).

O incremento em diâmetro para 18 anos foi de 3,28 cm/ano, e para 25 anos foi de 2,58 cm/ano. Essas árvores de A. macrocarpa produziram 15,33 m³/ha/ano na idade de 18 anos e 16,80 m³/ha/ano com 25 anos (Tabela 4). Segundo Carvalho (1994), o desenvolvimento do angico é de moderado a rápido, podendo atingir uma produtividade de até 25,55 $\mathrm{m}^{3} / \mathrm{ha} / \mathrm{ano}$. Os valores encontrados podem ser considerados satisfatórios, pois as árvores mensuradas estão em ambiente urbano, sujeitas as variações do micro clima urbano e condições de poluição da cidade e ainda em processo de crescimento. 
Os resultados deste estudo demonstram a existência do potencial da espécie para a produção de madeira em áreas urbanas. Segundo Carvalho (1994), o angico pode ser cortado a partir de 5 anos do plantio para mourões, aos 6 anos para lenha, nas dimensões de 8 a $12 \mathrm{~cm}$ de diâmetro e aos 20 a 25 anos para madeira de serraria.

A partir dos resultados obtidos, sugere-se o plantio de angico em áreas de estacionamento de veículos pela grande área de cobertura produzida pelas copas, em média $12,6 \mathrm{~m}^{2}$ por árvore. Nas zonas do entorno das cidades do Distrito Federal pode-se plantar em áreas de chácaras e sítios. A espécie apresenta grande potencial na produção de lenha para atender padarias, pizzarias e olarias; como madeira na construção civil e mourões. No caso do plantio comercial em pequenas áreas, uma redução no espaçamento reduziria o diâmetro das copas entre plantas visando conferir aos indivíduos um maior crescimento de fuste em detrimento ao diâmetro da copa. Carvalho (1994) cita plantios experimentais em que se utilizou uma área de 4 a $12 \mathrm{~m}^{2}$ por planta. De acordo com Machado et al. (1992) o angico se desenvolveu satisfatoriamente inclusive plantado em espaçamentos de 10 a $15 \mathrm{~m}^{2}$. Pelos resultados deste trabalho pode-se realizar um intensivo sistema de plantio consorciado com cultivares agrícolas. Em plantios que tenham como objetivo a produção de madeira o espaçamento pode ficar algo em torno de $3 \times 3 \mathrm{~m}$, (9 $\mathrm{m}^{2}$ por planta), para a região geo-econômica de Brasília. Espaçamentos muito reduzidos poderão acarretar um estresse às plantas, visto que o período seco na região é prolongado e o solo pobre em nutrientes.

Aroeira - Myracrodruon urundeuva Allemao, família: Anacardiaceae (TROPICOS, 2008)

A espécie Myracrodruon urundeuva ocorre desde a área de caatinga no estado do Ceará até os estados do Paraná e Mato Grosso do Sul (LORENZI, 2002). Além da ornamentação e paisagismo, segundo Lorenzi (2002) a espécie possui uma madeira pesada (densidade 1,19 $\mathrm{g} / \mathrm{cm}^{3}$ ), excelente para obras externas, moirões, estacas, dormentes, vigas e outros produtos que necessitam de maior rigidez. Sua casca é muito utilizada pela fitoterapia como antiinflamatório, cicatrizante e adstringente (IBGE, 2002). Como aspectos negativos ao uso da aroeira para a arborização em geral, deve-se considerar os princípios alérgicos e a queda das folhas verificadas no período de inverno (LORENZI, 2002).

A Tabela 3 mostra os resultados obtidos na avaliação dos indivíduos arbóreos (Figura 2) mensurados da espécie M. urundeuva, nas idades de 14 e 25 anos, obtidos respectivamente para os anos de 2000 e 2007. 
Análise silvicultural do angico e da aroeira...

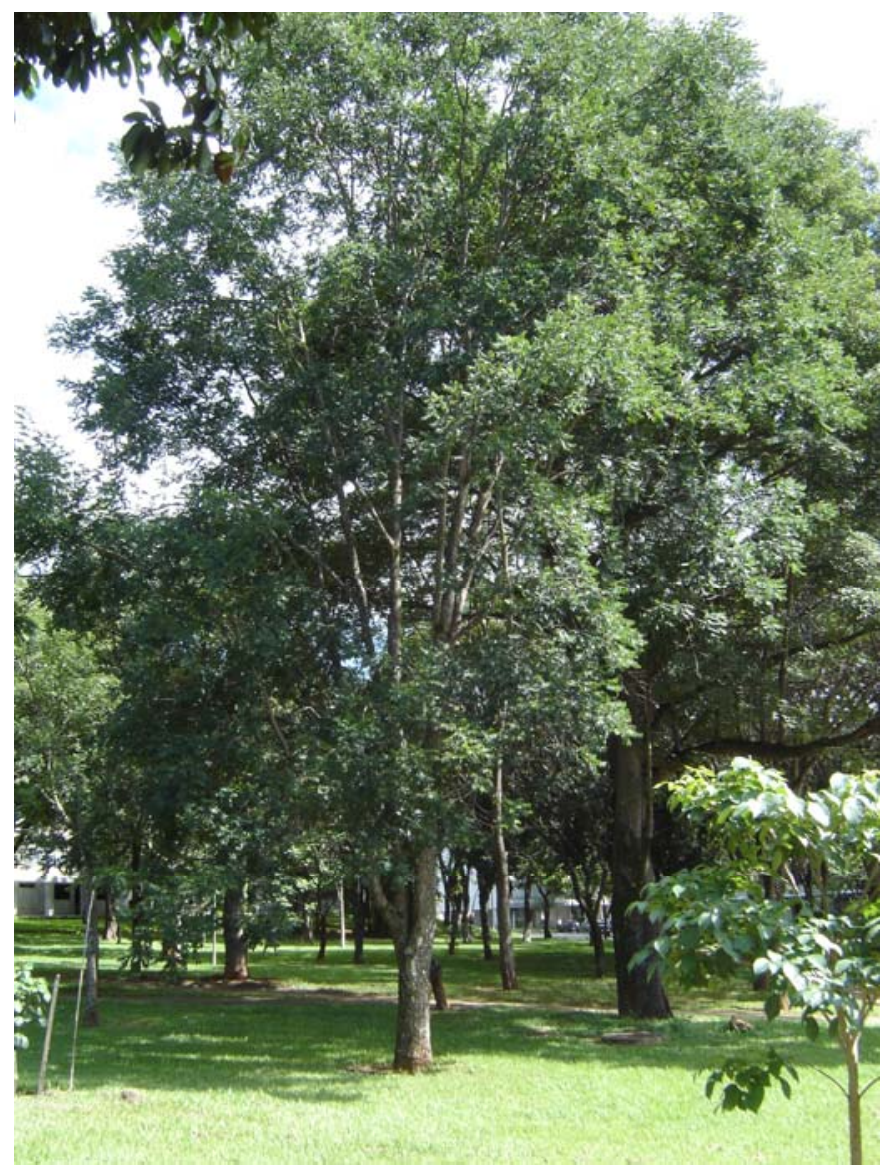

Figura 2 - Indivíduos de M. urundeuva mensurados na SQN 406, Brasília, DF.

Tabela 3 - Resultados das variáveis dendrométricas consideradas

\begin{tabular}{lc}
\hline Dados da Espécie & Myracrodruon urundeuva \\
\hline Idade & $\mathbf{1 4}$ anos \\
DAP médio & $26,8 \mathrm{~cm}$ \\
CV \% & 23,1 \\
H média 1 ${ }^{\text {a bifurcação }}$ & $2,7 \mathrm{~m}$ \\
H média início da copa & $3,5 \mathrm{~m}$ \\
H média total & $13,8 \mathrm{~m}$ \\
H média copa & $10,3 \mathrm{~m}$ \\
Diâmetro da Copa ( $\left.\mathrm{D}_{\text {copa }}\right)$ & $7,8 \mathrm{~m}$ \\
Idade & $\mathbf{2 1}$ anos \\
DAP médio & $31,0 \mathrm{~cm}$ \\
CV \% & 24,8 \\
H média 1 ${ }^{a}$ bifurcação & $3,2 \mathrm{~m}$ \\
H média início da copa & $5,7 \mathrm{~m}$ \\
H média total & $17,6 \mathrm{~m}$ \\
H média copa & $11,9 \mathrm{~m}$ \\
Diâmetro da Copa $\left(\mathrm{D}_{\text {copa }}\right)$ & $9,6 \mathrm{~m}$ \\
\hline
\end{tabular}


A aroeira apresentou aos 14 anos, indivíduos com 13,8 m de altura média, altura média do fuste até o início da copa igual a 3,5 m e DAP médio de $26,8 \mathrm{~cm}$. Na idade de 21 anos a espécie obteve um ganho percentual de 27,54\% em relação à altura média total, 62,86\% em relação à altura média do fuste até o início da copa, 23,08\% em relação ao diâmetro da copa projetado no solo e um ganho de $15,67 \%$ em relação ao DAP médio. Além das relações acima, a altura média da copa obteve um acréscimo de 15,53\% em relação às duas medições. Machado et al. (1990) cita que na avaliação de dez indivíduos de $M$. urundeuva, com idade de 12 anos, localizados no Parque da Cidade em Brasília, encontrou valores médios de 5,8 $\mathrm{m}$ de altura, 13,15 cm de DAP e 5,1 $\mathrm{m}$ de diâmetro da copa.

O incremento em diâmetro para os 14 anos foi de 1,91 cm/ano e para os 21 anos 1,48 $\mathrm{cm} / a n o$. As árvores de aroeira produziram 3,29 m³/ha/ano (Tabela 4), como produtividade estimada para um povoamento urbano de 14 anos de idade, e 2,86 m³/ha/ano nos 21 anos. Os decréscimos percebidos no incremento e na produtividade estimada em relação às duas medições ocorreram devido ao índice de mortalidade de 8,33\% encontrado para os indivíduos de aroeira. Segundo Carvalho (1994), o desenvolvimento da aroeira vai de lento a moderado, podendo atingir produtividade de até $5,5 \mathrm{~m} 3 / \mathrm{ha} / \mathrm{ano}$.

O M. urundeuva apresenta um bom desenvolvimento em Brasília. O sistema radicular é profundo não danificando passeios e vias de tráfego de veículos. Esses resultados conferem à espécie características desejáveis para a arborização urbana, principalmente, se consorciada a espécies perenifólias ou semicaducifólias. Os maiores desafios para a utilização de árvores do Cerrado em áreas públicas são a lentidão do crescimento e a sensibilidade do correspondente sistema radicular para o transplante (SILVA JÚNIOR et al., 2001).

A espécie, por ser nativa da região, apresenta um aspecto saudável e índice de crescimento volumétrico bastante satisfatório para uma espécie considerada de crescimento lento e, portanto, pouco utilizada em plantios comerciais. A aroeira pode ser indicada para plantios em parques e áreas verdes urbanas na região geo-econômia de Brasília, dada a sua característica estética, e o seu potencial de sombreamento. Pode-se utilizá-la para plantios às margens de avenidas e estradas urbanas e nas áreas do entorno, para produção de madeira e melhoria no ambiente local e na qualidade de vida da cidade.

De maneira geral as espécies estudadas podem ser indicadas para a formação de florestas urbanas, tanto na arborização da cidade como em áreas do entorno do Distrito Federal. Deve-se, no entanto, atentar para as características silviculturais próprias de cada uma, pois, dessa forma poderá ser possível otimizar os efeitos benéficos ao correspondente ambiente urbano com retorno econômico e bem-estar sociológico e fisiológico à sociedade local. 
Análise silvicultural do angico e da aroeira...

Tabela 4 - Análise da produção madeireira de duas espécies na arborização de Brasília

\begin{tabular}{cccccc}
\hline Espécie & $\begin{array}{c}\text { Idade } \\
\text { anos }\end{array}$ & $\begin{array}{c}\text { Volume } \\
\mathrm{m}^{3}\end{array}$ & $\begin{array}{c}\text { Volume } \\
\mathrm{m}^{3} / \mathrm{ha}\end{array}$ & $\begin{array}{c}\text { IMA } \\
\mathrm{m}^{3} / \mathrm{ha} / \mathrm{ano}\end{array}$ & $\begin{array}{c}\text { Projeção } \\
\text { para maior idade } \\
\mathrm{m}^{3} / \mathrm{ha}\end{array}$ \\
\hline \multirow{2}{*}{ A. macroparpa } & 18 & 1,38 & 276,00 & 15,33 & 383,33 \\
& 25 & 2,10 & 420,00 & 16,80 & \\
M. urundeuva & 14 & 0,23 & 46 & 3,29 & 69,00 \\
\hline
\end{tabular}

IMA = Incremento Médio Anual.

\section{CONCLUSÕES}

Os valores encontrados para o angico podem ser considerados excelentes, pois as árvores mensuradas estão em ambiente urbano, sujeitas as variações micro climáticas e condições de poluição. Os resultados apresentam o potencial do angico para a produção de madeira na região dos cerrados. Assim, sugere-se o plantio de angico nas zonas do entorno das cidades em pequenas áreas de chácaras na região do Distrito Federal.

A aroeira apresentou um bom desenvolvimento em Brasília. Os resultados conferem à espécie características desejáveis para a arborização urbana, principalmente, se consorciada a espécies perenifólias ou semicaducifólias.

Desta forma as espécies estudadas podem ser indicadas para a formação de florestas urbanas, tanto na arborização das cidades como em áreas do entorno do Distrito Federal.

\section{REFERÊNCIAS BIBLIOGRÁFICAS}

BIONDI, D.; ALTHAUS, M. Árvores de rua de Curitiba: cultivo e manejo. Curitiba: FUPEF, 2005. 182 p.

BRANDÃO, M.; BRANDÃO, H. A árvore: paisagismo e meio ambiente. Belo Horizonte: Editora Vitae Comunicação Integrada, 1992. 168 p.

CARTER, E.J. El potencial de la silvicultura urbana en los paises en desarrollo: conceptos. Santiago: FAO, 1996.

CARVALHO, P.E.R. Espécies florestais brasileiras: recomendações silviculturais, potencialidades e uso da madeira. Colombo: EMBRAPA-CNPF, 1994. 640 p. 
CESTARO, L.A. A vegetação no ecossistema urbano. In: ENCONTRO NACIONAL SOBRE ARBORIZAÇÃO URBANA. Anais. Porto Alegre, 1985. p. 51-56.

DETZEL, V. A Arborização urbana: Importância e avaliação econômica. In: I Congresso Brasileiro de Arborização Urbana. IV ENCONTRO NACIONAL SOBRE ARBORIZAÇÃO URBANA. Anais. Vol. I. Vitória - ES, 1992, p. 39-52.

EMBRAPA Solos do Distrito Federal. Rio de Janeiro: EMBRAPA/SNCLCS, 1978. 6 p. (Comunicado Técnico, 1)

GONÇALVES, W. Florestas urbanas, ação ambiental. Viçosa: Ano II (9), 1999. p. 17-19.

GONÇALVES, W.; PAIVA, H. N. de. Silvicultura urbana - implantação e manejo. Viçosa: Aprenda Fácil Editora, 2006.

IBGE. Instituto Brasileiro de Geografia e Estatística. Árvores do Brasil Central: espécies da região geoeconômica de Brasília. Rio de Janeiro: Diretoria de Geociências., 2002.

KUCHELMEISTER, G.; BRAATZ, S. Uma nueva visión de la silvicultura urbana. Unasylva. v. 44, n. 173, p. 3-12. 1993.

LEAL, L.; BIONDI, D.; ROCHADELLI, R. Investimentos destinados à arborização de ruas na cidade de Curitiba: uma abordagem a partir da Teoria de Renda da Terra. Scientia. Forestalis, Piracicaba, v. 36, n. 78, jun. 2008, p. 141-149.

LEWIS, R.K. Urban trees: serving the eye, environment, pocketbook and psyche. American Forests, v.103, n. 2, p. 22-25. 1997.

LOMBARDO, M. A. Vegetação e clima. In: ENCONTRO NACIONAL SOBRE ARBORIZAÇÃO URBANA, 3. Anais. Curitiba, 1990. p. 1-13.

LORENZI, H. Árvores brasileiras: manual de identificação e cultivo de plantas arbóreas do Brasil. vol 1. 4ª ed. São Paulo: Ed. Nova Odessa, 2002. 
Análise silvicultural do angico e da aroeira...

MACHADO, J.W.B.; ALENCAR, F.O.C.C.; RODRIGUES, M.G.R.; Árvores de Brasília. Brasília: GDF, Secretaria de Obras e Serviços Públicos, Departamento de Parques e Jardins, 1992. 100 p.

MACHADO, J.W.B.; RODRIGUES, M.G.R.; LIMA FILHO, R.M. Notas sobre o crescimento de árvores plantadas em Brasília. In: O JARDINEIRO. Brasília: Departamento de Parques e Jardins / DU / NOVACAP. 1990. p. 17-23.

MILANO, M S. O Planejamento da arborização, as necessidades de manejo e tratamentos culturais das árvores de ruas de Curitiba-PR. Revista do Centro de Pesquisas Florestais. v. 17, n. 1, p.15-21. 1987

NIMER, E. Climatologia do Brasil. Rio de Janeiro: IBGE, Departamento de Recursos Naturais e Estudos Ambientais, 1989.

PEREIRA, R.I. A vegetação e o espaço urbano. In: Paisagismo: a visão ambiental da paisagem. Curso. Brasília, 1998. p.103-131.

PINTO, M.N. et al. Cerrado: caracterização, ocupação e perspectivas. Brasília: Editora Universidade de Brasília, 1993. $2^{\mathrm{a}}$ ed. 681 p.

RIZZINI, C.T. Árvores e madeiras úteis do Brasil: manual de dendrologia brasileira. $2^{a}$ Ed. São Paulo: Ed. Edgard Blücher, 1987.

ROSSATTO, D.R.; TSUBOY, M.S.F.; FREI, F. Arborização urbana na cidade de Assis-SP: uma abordagem quantitativa. Rev. SBAU, Piracicaba, v.3, n.3, set. 2008, p. 1-16.

SETH, M.K. Trees and their economic importance. The Botanical Review, Lancaster, v. 69, n. 4, p. 321- 376. 2004.

SILVA JÚNIOR, M. C. da; CORREIA, C. R. M. de A. Arborização no Campus da Universidade de Brasília. In: ENCONTRO NACIONAL DE ARBORIZAÇÃO URBANA, 9., 001, Brasília, DF. Resumos... Brasília, DF: [s.n.], 2001. 26 p.

SILVA JÚNIOR, M. C. da; FARIAS, S. B.; SANCHEZ, M.; SOUZA, R. C. P. F. Avaliação da arborização urbana em Brasília: contribuição para a restruturação do cerrado. In: 
ENCONTRO NACIONAL DE ARBORIZAÇÃO URBANA, 9., 001, Brasília, DF. Resumos... Brasília, DF: [s.n.], 2001. p. 37.

TROPICOS. Missouri Botanical Garden. 2008. Disponível em: http://www.tropicos.org. Acesso em: 27/03/2008. 